\title{
Mortality Attributable to Nosocomial Infection: A Cohort of Patients With and Without Nosocomial Infection in a French University Hospital
}

\author{
Pascale Fabbro-Peray, MD, PhD; A. Sotto, MD, PhD; C. Defez, MD; M. Cazaban, MD; L. Molinari, BSc; \\ M. Pinède, BSc; A. Mahamat, MD; J.P. Daurès, MD, PhD
}

OBJECTIVE To assess nosocomial infection (NI) as a risk factor for death and to estimate the population-attributable risk of death from NI. DESIGN. A prospective cohort study of patients with and without NI.

SETting. Nîmes University Hospital, Nîmes, France.

PATiEnts. Patients were recruited from May 7, 2001, to January 10, 2003. Patients in acute care and long-term care units who had NI were enrolled, and patients without NI were randomly selected and matched with patients with NI for age, sex, type of care (acute care vs. long-term care) and length of stay in hospital at study inclusion.

OUTCOME MEASURES. Vital status within 60 days after study inclusion was assessed. We used conditional logistic regression to estimate the relative death risk from NI after adjusting for comorbidities, severity of the underlying disease, and all other confounding factors. The adjusted population-attributable risk was assessed using the Mantel-Haenszel method.

RESULTS. We recruited 1,914 patients with NI and 5,172 patients without NI. The median age of the patients with NI was 73 years; $1,045(54.6 \%)$ were female. NI was associated with death within 60 days (adjusted odds ratio, 1.7 [95\% confidence interval $\{\mathrm{CI}\}, 1.4-; 2.2]$; $P<.001)$. The adjusted population-attributable risk of death for all sites of infection was $1.7 \%(95 \% \mathrm{CI}, 1.4-2.1)$. If we consider the NI incidence to be $3 \%-6 \%$ in French hospitals, the population-attributable risk of death from NI would range from $2.1 \%(95 \% \mathrm{CI}, 1.7 \%$ $2.5 \%)$ to $4.0 \%(95 \% \mathrm{CI}, 3.3 \%-4.9 \%)$.

CONCLUSion. In this study, NI appeared to have a significant impact on mortality. Multicenter studies will be needed to confirm these results.

Infect Control Hosp Epidemiol 2007; 28:265-272

Nosocomial infection (NI) is a major public health problem, with an estimated incidence in Europe of $3 \%^{1}$ to $6 \% .^{2} \mathrm{Al}-$ though other studies have assessed the microorganisms most frequently responsible for NIs, the most common infection sites of NIs, and the associated economic costs, the mortality attributable to NI remains largely unknown. Although not based on scientific evidence, a frequently quoted estimation for France is 10,000 deaths per year. ${ }^{3}$

A major complexity in directly attributing mortality to NI is the fact that infected patients often experience severe underlying diseases or conditions, which may themselves be risk factors for death. Most previous studies have analyzed mortality due to NI by 1 of 3 different methods: (1) descriptive analysis that used patient records to attribute death to $\mathrm{NI}^{4}$ (such studies, however, are often retrospective and lack proper controls); (2) comparative analysis that determined mortality due to NI by adjusting for or matching for other risk factors (such studies, however, most often involve only one type of ward $^{56-12}$ or one site of infection $\left.{ }^{7-14}\right)$; and (3) analysis of data collected from death certificates ${ }^{15}$ (such studies are difficult to interpret because of the considerable number of missing data points). In the present study we attempted to determine the degree to which NI is a risk factor for death on a hospitalwide basis and, furthermore, to estimate the number of deaths caused by NI.

\section{METHODS}

This prospective study of patients with and without $\mathrm{NI}$ was performed within the Nîmes University Hospital in Nîmes, France. This hospital has 833 acute care beds, including 39 in the intensive care unit (ICU), 399 in the medical unit, 223 in the surgery unit, 54 in the obstetrics and gynecology unit, and 118 in the psychiatry unit; 268 long-term care beds, including beds in the physical medicine and rehabilitation units; and 483 beds in the skilled nursing unit.

From the Département de l'Information Médicale (P.F.-P., C.D., L.M., M.P., A.M., J.P.D.), Comite de Lutte contre les Infections Nosocomiales (A.S.), and Equipe Opérationnelle d'Hygiène (M.C.), Groupe hospitalier Carémeau, Nîmes, and Laboratoire de biostatistiques et d'épidémiologie, Institut Universitaire de Recherche Clinique, Université Montpellier I, Montpellier (P.F.-P., A.S., M.C., A.M., J.P.D.), France.

Received January 31, 2006; accepted June 14, 2006; electronically published February 20, 2007.

(C) 2007 by The Society for Healthcare Epidemiology of America. All rights reserved. 0899-823X/2007/2803-0003\$15.00. DOI: 10.1086/512626 
TABLE 1. Demographic and Clinical Characteristics of Patients With and Patients Without Nosocomial Infection (NI) at Nîmes University Hospital, 2001-2003

\begin{tabular}{|c|c|c|c|}
\hline Characteristic & $\begin{array}{l}\text { Patients with NI } \\
\quad(n=1,914)\end{array}$ & $\begin{array}{l}\text { Patients without NI } \\
\quad(n=5,172)\end{array}$ & $P$ \\
\hline Age, $y$ & & & .10 \\
\hline Mean $\pm \mathrm{SD}$ & $69 \pm 18$ & $68 \pm 18$ & \\
\hline Median (5th-95th percentile) & $73(32-91)$ & $73(31-90)$ & \\
\hline Interval from admission to study inclusion, $\mathrm{d}$ & & & $<.001$ \\
\hline Mean $\pm \mathrm{SD}$ & $15 \pm 15$ & $13 \pm 11$ & \\
\hline Median (5th-9th percentile) & $10.5(3-43)$ & $9(2-35)$ & \\
\hline Age group & & & .60 \\
\hline$\leqslant 35 y$ & $125(6.5)$ & $362(7.0)$ & \\
\hline $36-45 y$ & $114(6.0)$ & $315(6.1)$ & \\
\hline $46-55 y$ & $180(9.4)$ & $516(10.0)$ & \\
\hline $56-65 y$ & $213(11.1)$ & $582(11.3)$ & \\
\hline $66-70 y$ & $188(9.8)$ & $495(9.6)$ & \\
\hline $71-75 y$ & $226(11.8)$ & $660(12.8)$ & \\
\hline $76-80 y$ & $292(15.3)$ & $778(15.0)$ & \\
\hline $81-85 y$ & $264(13.8)$ & $689(13.3)$ & \\
\hline$>85 y$ & $312(16.3)$ & $775(15.0)$ & \\
\hline Interval from admission to study inclusion, $\mathrm{d}$ & & & $<.001$ \\
\hline$\leqslant 5 \mathrm{~d}$ & $416(21.7)$ & $1,401(27.1)$ & \\
\hline $6-10 \mathrm{~d}$ & $541(28.3)$ & $1,525(29.5)$ & \\
\hline $11-15 \mathrm{~d}$ & $344(18.0)$ & $888(17.2)$ & \\
\hline $16-20 \mathrm{~d}$ & $200(10.4)$ & $462(8.9)$ & \\
\hline $21-25 \mathrm{~d}$ & $128(6.7)$ & $275(5.3)$ & \\
\hline $25-30 \mathrm{~d}$ & $79(4.1)$ & $209(4.0)$ & \\
\hline$>30 \mathrm{~d}$ & $206(10.8)$ & $412(8.0)$ & \\
\hline Ward of hospitalization & & & $<.001$ \\
\hline Long-term care & $261(13.6)$ & $1,083(20.9)$ & \\
\hline Acute care & $1,653(86.4)$ & $4,089(79.1)$ & \\
\hline Medicine or cancer ${ }^{a}$ & $247(12.9)$ & $877(17.0)$ & \\
\hline Internal medicine & $327(17.1)$ & $985(19.0)$ & \\
\hline Other medicine & $233(12.2)$ & $957(18.5)$ & \\
\hline Orthopedic surgery & $185(9.7)$ & $394(7.6)$ & \\
\hline Digestive surgery & $206(10.8)$ & $267(5.2)$ & \\
\hline Other surgery & $216(11.3)$ & $561(10.9)$ & \\
\hline $\mathrm{ICU}$ & $239(12.5)$ & $48(1.0)$ & \\
\hline Vital status at $60 \mathrm{~d}$ & & & $<.001$ \\
\hline Died & $413(21.6)$ & $429(8.3)$ & \\
\hline Lost to follow-up & $38(2)$ & $99(1.9)$ & \\
\hline
\end{tabular}

NOTE. Data are no. (\%) of patients, unless otherwise specified. ICU, intensive care unit.

"Medicine departments where cancer could be treated.

Every year, approximately 40,000 patients are admitted to the hospital. We defined the presence of an NI according to the French standardized definition, ${ }^{16}$ which is similar to the one used by the Centers for Disease Control and Prevention. ${ }^{17}$

\section{Recruitment of Patients}

We included all patients hospitalized in acute care units (excluding day patients and patients in the brain injury ward $[8$ beds] and the neonatal ward [ 30 beds]) and in longer-term care units who had contracted an NI during their stay. Patients were included after the first episode of NI for each individual hospital stay but only once for a given stay. It was, however, possible to include the same patient more than once if this patient contracted a new NI during a subsequent hospital stay or if the patient was classified as not having an NI during the succeeding hospital stay.

Once enrolled, each patient with NI was randomly matched with 3 patients without NI chosen from the hospital database. The matching criteria were age (plus or minus 5 years), sex, location of stay in the hospital (acute care unit or long-term care unit), and length of stay in the hospital at inclusion (plus or minus 5 days until 30 days, then greater than 30 days). A patient without NI would be classified as a patient with NI if he or she developed an NI within 7 days after selection. Patients who had contracted an NI from another institution or from the skilled nursing department within the hospital 
TABLE 2. Sites of Nosocomial Infection (NI) Among Patients at Nîmes University Hospital, 2001-2003

\begin{tabular}{lc}
\hline Class and site of NI & No. (\%) of patients \\
\hline One site of infection & $1,745(91.2)$ \\
Urinary tract infection & $1,066(55.7)$ \\
Surgical site infection & $218(11.4)$ \\
Pneumonia & $212(11.1)$ \\
Bloodstream infection & $147(7.7)$ \\
Catheter-related local infection & $36(1.9)$ \\
Skin and soft-tissue infection & $36(1.9)$ \\
Gastrointestinal tract infection & $12(0.6)$ \\
Other & $18(0.9)$ \\
More than one site of infection & $169(8.9)$ \\
\hline
\end{tabular}

were not included. The inclusion date was the date of diagnosis of the NI for patients with NI and the date of the random classification for patients without NI.

\section{System for Optimizing NI Data Collection}

We collected the data from the hospital's bacteriological samples database (the list of all patients from whom samples were taken, whether samples tested positive or negative for a pathogen) and from the antibiotic prescriptions database. After this initial screening, the clinical research assistants consulted the patient's physician in the clinical services to verify all information extracted from the 2 databases. At the same time, the physicians were queried as to the existence of other NIs not noted in the 2 databases.

\section{Data Collection}

Data were collected using a standardized questionnaire completed on the basis of the patient's medical record and interviews with the patient and the physician in charge of the patient. The following clinical characteristics were recorded for all included patients: sociodemographic characteristics, date of admission, mode of admission, McCabe score on admission ${ }^{18}$ type of disease and comorbidities on admission (to calculate the Charlson index ${ }^{19,20}$ ), interventions and their corresponding dates and durations, date of discharge, and hospital outcome (vital status). For patients with NI, the type of microorganism and the isolate's antibiotic susceptibility phenotype were recorded on the basis of the bacteriological database. The drug-susceptibility classifications "susceptible," "intermediate," and "resistant" were assigned according to the guidelines of the Antibiogram Committee of the French Society of Microbiology. Definitions for multidrug resistance in the different bacteria were those recommended in the relevant French regional database. ${ }^{21}$

The main outcome was vital status of the patient within 60 days after inclusion in the study. We obtained this information from either the hospital database or a search of the French national vital statistics database (available at http:// ifr69.vjf.inserm.fr).

\section{Sample Size}

The likelihood of death among patients with NI varies from $6 \%$ to $15 \%$ for all sites of infection evaluated. ${ }^{22-24}$ The estimate of the relative risk of death for hospitalized patients with NI, compared with hospitalized patients without NI, is approximately $1.5 .^{14}$ Therefore, we needed to include a minimum of 1,856 patients with NI and 3,712 patients without NI (1 patient with NI per 2 patients without NI) to reach $95 \%$ power and a bilateral $\alpha$ risk of $.05 .{ }^{25}$ To ensure this $1: 2$ ratio (since a patient without NI can potentially become a patient with NI), 3 patients without NI were selected for each patient with NI.

\section{Statistical Analysis}

For all the potential risk factors, we estimated the crude odds ratios (ORs) for death and 95\% confidence intervals (CIs) using an univariate conditional logistic regression. ${ }^{25}$ We estimated adjusted ORs (aORs) using conditional logistic regression as follows: for each section of the questionnaire (ie, characteristics of the hospital stay for each patient, comorbidities, intervention variables) a conditional logistic regression model was used to select the most informative variables, which were then used in a global multivariate logistic model to control for all the confounding factors, as described by Hosmer and Lemeshow. ${ }^{25}$ The absence of colinearity among the variables was confirmed in the manner described by Belsley et al..$^{27}$ For building the models, we applied a forward stepwise introduction of variables $(P=.10)$. The aORs and their $95 \%$ CIs were derived from the estimated regression coefficients.

We calculated the proportion of deaths attributable to NI in the population by means of the adjusted population-attributable risk (PAR), estimated with the Mantel-Haenszel formula $^{28,29}$ as $\mathrm{PAR}=p(\mathrm{aOR}-1) / p(\mathrm{aOR}-1)+1$, where $p$ is the incidence rate of NI. We calculated the $95 \% \mathrm{CI}$ for the

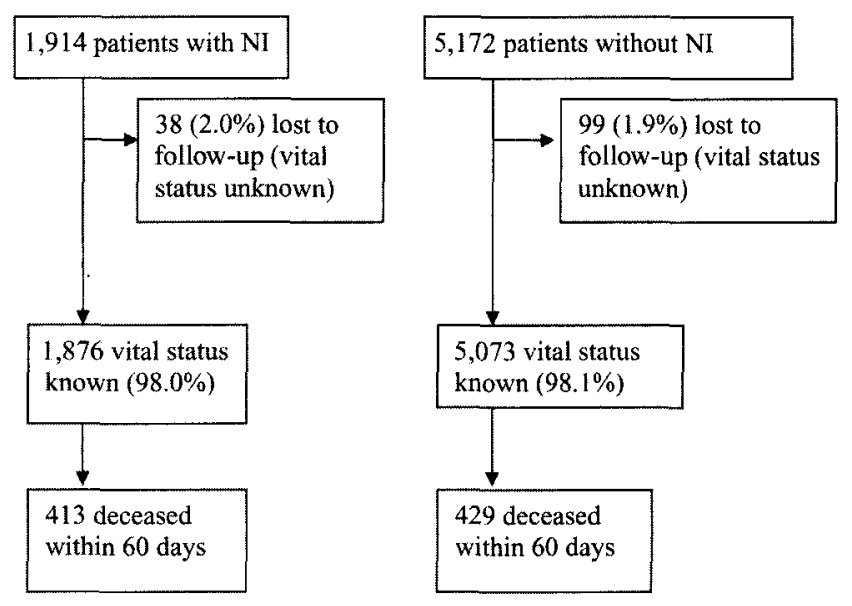

FIGURE. Diagram showing follow-up of patients included in the study, Nîmes University Hospital, 2001-2003. 
TABLE 3. Univariate Analysis of Factors Associated With Death Within 60 Days Among Patients with Nosocomial Infection at Nîmes University Hospital, 2001-2003

\begin{tabular}{|c|c|c|c|}
\hline Variable & $\begin{array}{l}\text { Patients who died } \\
\quad(n=842)\end{array}$ & $\begin{array}{l}\text { Patients who survived } \\
\qquad(n=6,107)\end{array}$ & $P$ \\
\hline Nosocomial infection present & $413(49.0)$ & $1463(24.0)$ & $<.001$ \\
\hline Provenance of the patient & & & .10 \\
\hline Home & $801(95.1)$ & $5,619(92.0)$ & \\
\hline Another institution & $41(4.9)$ & $488(8.0)$ & \\
\hline McCabe score & & & $<.001$ \\
\hline 0 & $117(13.9)$ & $4,007(65.6)$ & \\
\hline 1 & $360(42.8)$ & $1,766(28.9)$ & \\
\hline 2 & $365(43.4)$ & $334(5.5)$ & \\
\hline Charlson index & & & $<.001$ \\
\hline$<3$ & $530(62.9)$ & $5,024(82.3)$ & \\
\hline$\geqslant 3$ & $312(37.1)$ & $1,083(17.7)$ & \\
\hline \multicolumn{4}{|l|}{ Comorbidity } \\
\hline Hemiplegia & $53(6.3)$ & $322(5.3)$ & .07 \\
\hline Solid tumor without metastasis & $92(11.0)$ & $324(5.3)$ & $<.001$ \\
\hline Solid tumor with metastasis & $110(13.1)$ & $136(2.2)$ & $<.001$ \\
\hline Leukemia & $16(1.9)$ & $40(0.7)$ & .006 \\
\hline Lymphoma & $28(3.3)$ & $73(1.2)$ & .002 \\
\hline Dementia & $64(7.6)$ & $281(4.6)$ & .11 \\
\hline Complicated diabetes mellitus & $7(0.8)$ & $128(2.1)$ & .04 \\
\hline Noncomplicated diabetes mellitus & $151(17.9)$ & $1,091(17.9)$ & .49 \\
\hline Myocardial infarction & $118(14.0)$ & $649(10.6)$ & .66 \\
\hline Stroke & $134(15.9)$ & $711(11.6)$ & .29 \\
\hline Congestive heart failure & $121(14.4)$ & $506(8.3)$ & .02 \\
\hline Renal failure & $35(4.2)$ & $143(2.3)$ & .006 \\
\hline Peripheral vascular disease & $85(10.1)$ & $401(6.6)$ & .28 \\
\hline Chronic bronchopulmonary disease & $85(10.1)$ & $555(9.1)$ & .29 \\
\hline Connective tissue disease & $13(1.6)$ & $78(1.3)$ & .95 \\
\hline Peptic ulcer disease & $27(3.2)$ & $223(3.7)$ & .21 \\
\hline Slight hepatic failure & $19(2.3)$ & $132(2.2)$ & 1 \\
\hline Severe hepatic failure & $28(3.3)$ & $90(1.5)$ & .005 \\
\hline AIDS & $6(0.7)$ & $20(0.3)$ & .003 \\
\hline \multicolumn{4}{|l|}{$\begin{array}{l}\text { Invasive procedure or device placed } \\
\text { during hospitalization }\end{array}$} \\
\hline Arterial catheter & $72(8.6)$ & $182(3.0)$ & $<.001$ \\
\hline Central venous catheter & $125(14.9)$ & $432(7.1)$ & $<.001$ \\
\hline Peripheral venous catheter & $682(81.0)$ & $3,917(64.1)$ & $<.001$ \\
\hline Mechanical ventilation & $94(11.2)$ & $327(5.4)$ & $<.001$ \\
\hline Intubation & $88(10.5)$ & $286(4.7)$ & $<.001$ \\
\hline Implantable venous catheter & $87(10.3)$ & $164(2.7)$ & $<.001$ \\
\hline Urinary catheter & $308(36.6)$ & $1,340(21.9)$ & $<.001$ \\
\hline Surgical procedure & & & $<.001$ \\
\hline None & $723(85.9)$ & $4,933(80.8)$ & \\
\hline 1 & $78(9.3)$ & $556(9.1)$ & \\
\hline$>1$ & $41(4.9)$ & $618(10.1)$ & \\
\hline Charlson index, median (5th-95th percentile) & $2(0-7)$ & $1(0-5)$ & $<.001$ \\
\hline
\end{tabular}

NOTE. Data are no. (\%) of patients, unless indicated otherwise. AIDS, acquired immunodeficiency syndrome.

PAR values using the exponential transformation of standard error (SE) of the $\beta$ coefficient of the logistic regression for each given class of NI (ie, all NIs, urinary tract infection [UTI], bacteremia, pneumonia, and NI with more than 1 site of infection). Thus, the $95 \% \mathrm{CI}$ of the PAR value was calculated as $\mathrm{PAR} \pm \mathrm{SE}_{\mathrm{PARa}} \times 1.96$. Statistical analysis was performed using SAS software, version 8.1 (SAS Institute).

\section{Ethical Approval}

We obtained agreements from the department heads of each clinical service involved. The study protocol was submitted to the consulting committee for the treatment of information for medical research studies and to the National Commission for the Freedom of Information, which gave their approval on January 12, 2001, and December 18, 2001, respectively.

\section{RESULTS}

From May 7, 2001, to January 10, 2003, we included 1,914 patients with NI ( 1,872 confirmed and 42 probable infections) during their hospitalization in our study. We also included 5,172 patients without NI. Table 1 summarizes the distri- 
TA B LE 4. Multivariate Analysis of Risk of Death Within 60 Days With Adjustment for McCabe Score Among Patients with Nosocomial Infection (NI) at Nîmes University Hospital, 2001-2003

\begin{tabular}{|c|c|c|c|c|}
\hline Variable & $\begin{array}{l}\text { Adjusted OR } \\
(95 \% \mathrm{CI})\end{array}$ & $P$ & $\begin{array}{c}\text { Incidence, } \\
\text { NIs per } 1,000 \\
\text { hospitalizations }\end{array}$ & $\begin{array}{c}\text { PAR, } \\
\%(95 \% \mathrm{CI})\end{array}$ \\
\hline \multicolumn{5}{|l|}{ NI present } \\
\hline No & 1 & & $\ldots$ & $\ldots$ \\
\hline Yes & $1.7(1.4-2.2)$ & $<.001$ & 25 & $1.7(1.4-2.1)$ \\
\hline \multicolumn{5}{|l|}{ One site of infection } \\
\hline Bloodstream infection & $2.8(1.4-5.6])$ & .004 & 2 & $0.3(0.2-0.6])$ \\
\hline Pneumonia & $2.3(1.3-4.1)$ & .003 & 3 & $0.4(0.2-0.6)$ \\
\hline Urinary tract infection & $1.4(1.0-1.8)$ & .03 & 15 & $0.6(0.4-0.8)$ \\
\hline Surgical site infection & $1.4(0.7-3.1)$ & .36 & $\ldots$ & $\ldots$ \\
\hline Catheter-related local infection & $0.9(0.1-7.9)$ & .89 & $\ldots$ & $\ldots$ \\
\hline Gastrointestinal tract infection & $6.5(0.4-109.7)$ & .19 & ... & $\cdots$ \\
\hline Skin and soft-tissue infection & $2.7(0.3-23.3)$ & .37 & $\ldots$ & $\ldots$ \\
\hline Other & $8.3(0.8-91.3)$ & .09 & $\ldots$ & $\ldots$ \\
\hline More than one site of infection & $2.6(1.4-4.8)$ & .001 & 2 & $0.4(0.2-0.5)$ \\
\hline
\end{tabular}

NOTE. For details about variables adjusted for in the OR calculation, see Methods. CI, confidence interval; NI, nosocomial infection; OR, odds ratio; PAR, population-attributable risk.

bution of patients with and without NI with respect to demographic and clinical characteristics. Of the 1,914 patients with NI, $1,045(54.6 \%)$ were female. The median age of these patients was 73 years (5th percentile, 32 years; 95 th percentile, 91 years). The median time between admission and NI diagnosis was 10.5 days (5th percentile, 3 days; 95 th percentile, 43 days). Most of the patients with NI were hospitalized in the acute care unit ( $86.4 \%$ of patients), divided among the medical unit $(42.2 \%)$, surgical unit $(31.7 \%)$ and intensive care unit (ICU) (12.5\%).

It was difficult to closely match patients with and without NI for the location of hospital stay, particularly for those hospitalized in the acute care unit who had a long interval between admission and NI diagnosis. In this case, we matched patients with respect to the duration of the hospitalization.

A total of 2,094 NIs had the site of infection reported: $1,174(56.1 \%)$ were UTI infections, $261(12.5 \%)$ were surgical site infections, $265(12.7 \%)$ were cases of pneumonia, and $245(11.7 \%)$ were bloodstream infections. Among the patients with NI, $169(8.9 \%)$ developed infection at least 2 simultaneous sites. The principal microorganisms isolated were Escherichia coli (in $29.7 \%$ of cases), Staphylococcus aureus (in 13.9\%), and Pseudomonas aeruginosa (in 8.5\%). In 195 patients $(10.4 \%)$, at least 1 multidrug-resistant strain of bacteria was found. Table 2 presents the distribution of the sites of infection. Vital status at 60 days was recorded for 6,949 $(98.1 \%)$ of the patients; $2 \%$ of the patients in each group were lost to follow-up (Figure). A total of 101 patients with NI $(24.5 \%)$ and 168 patients without NI (39.2\%) died after leaving the hospital.

Using univariate analysis, we compared the living and deceased patients with respect to whether NI was the main risk factor and with respect to other confounding risk factors (Table 3). The percentage of NIs was greater for the group of patients who had died (crude OR, 3.2 [95\% CI, 2.7-3.7]; $P<.001)$. The OR was similar whether there was at least 1 multidrug-resistant bacterial strain or not (crude ORs, 3.2 [95\% CI, 2.0-5.1]; $P<.001)$ or not $(3.2$ [95\% CI, 2.7-3.7]; $P<.001)$.

Presence of an NI (no vs yes) and class of NI (none, bloodstream infection, pneumonia, UTI, surgical site infection, catheter-related local infection, gastrointestinal tract infection, skin and soft-tissue infection, others, more than 1 site of infection) were systematically included in the models. The univariate analysis and the previous multivariate analysis allowed us to select the following variables for a global multivariate conditional logistic model: ward of hospitalization (long-term care, medicine or cancer unit, internal medicine, other medicine, orthopedic surgery, other surgery, ICU), provenance of the patient (ie, ward or institution from which the patient was admitted), time between study inclusion and admission, McCabe score, Charlson index, peripheral catheter, urinary catheter, mechanical ventilation, endotracheal intubation, arterial catheter, central venous catheter, implantable venous catheter, and surgical procedure. With adjustment for McCabe score, the goodness of fit, based on Schwarz criteria, was 1,214.96 for presence of NI at any site and was $1,413.76$ for NI at specific sites (Table 4). With adjustment for Charlson index, the goodness of fit, based on Schwarz criteria, was 1,264.49 for presence of NI at any site and was $1,449.52$ for NI at specific sites (Table 5). The adjusted ORs (ie, the estimated relative risk of dying for patients with NI) were smaller than the unadjusted ORs but remained statistically significant after adjustment for the McCabe score (OR, 1.7 [95\% CI, 1.4-2.2]; $P<.001)$ and for the Charlson index (OR, 2.2 [95\% CI, 1.8-2.6]; $P<.001$ ). In the 2 models, bloodstream infections, pneumonia, UTIs, and more than 1 infection site were the classes of infection significantly linked to 
TABLE 5. Multivariate Analysis With Adjustment for the Charlson Index for Risk of Death Among Patients with Nosocomial Infection (NI) at Nîmes University Hospital, 2001-2003

\begin{tabular}{|c|c|c|c|c|}
\hline Variable & $\begin{array}{l}\text { Adjusted OR } \\
(95 \% \mathrm{CI})\end{array}$ & $P$ & $\begin{array}{c}\text { Incidence, } \\
\text { NIs per } 1,000 \\
\text { hospitalizations }\end{array}$ & $\begin{array}{c}\text { PAR } \\
\%,(95 \% \text { CI })\end{array}$ \\
\hline \multicolumn{5}{|l|}{ NI present } \\
\hline No & 1 & & $\cdots$ & ... \\
\hline Yes & $2.2(1.8-2.6)$ & $<.001$ & 25 & $3.0(2.5-3.4)$ \\
\hline \multicolumn{5}{|l|}{ One site of infection } \\
\hline Bloodstream infection & $3.9(2.0-7.4)$ & $<.001$ & 2 & $0.5(0.4-0.7)$ \\
\hline Pneumonia & $3.4(2.0-5.7)$ & $<.001$ & 3 & $0.6(0.5-0.8)$ \\
\hline Urinary tract infection & $1.6(1.3-2.1)$ & $<.001$ & 15 & $0.9(0.6-1.1)$ \\
\hline Surgical site infection & $1.7(0.9-3.3)$ & .14 & $\ldots$ & $\ldots$ \\
\hline Catheter-related local infection & $1.3(0.2-10.1])$ & .79 & $\ldots$ & $\ldots$ \\
\hline Gastrointestinal tract infection & $6.0(0.6-57.0)$ & .12 & $\ldots$ & $\ldots$ \\
\hline Skin and soft-tissue infection & $2.6(0.4-15.9)$ & .31 & $\ldots$ & $\ldots$ \\
\hline Other & $10.6(1.0-106.5)$ & .05 & $\ldots$ & $\ldots$ \\
\hline More than 1 site of infection & $3.3(1.9-5.6)$ & $<.001$ & 2 & $0.5(0.4-0.6)$ \\
\hline
\end{tabular}

NOTE. For details about variables adjusted for in the OR calculation, see Methods. CI, confidence interval; NI, nosocomial infection.

death within 60 days. The PAR of death for all infected sites was $1.7 \%(95 \% \mathrm{CI}, 1.4-2.1)$ with adjustment for the McCabe score and 3.0\% (95\% CI, 2.5-3.4) with adjustment for the Charlson index. For the different sites of infection, the adjusted ORs and the PAR of deaths are outlined in Tables 4 and 5.

If we consider the incidence of NI to be 3\%-6\% in French hospitals, the PAR for death from NI should be from $2.1 \%$ (95\% CI, $1.7 \%-2.5 \%)$ to $4.0 \%(95 \% \mathrm{CI}, 3.3 \%-4.9 \%)$ with adjustment for McCabe score, and it should be from 3.5\% (95\% CI, 3.0\%-4.0\%) to $6.7 \%(95 \% \mathrm{CI}, 5.8 \%-7.7 \%$ ) with adjustment for the Charlson index.

\section{DISCUSSION}

The main aims of our study were to demonstrate the association between NI and mortality and to quantify the fraction of hospitalized patients in whom NI was likely to contribute to death. The availability of a large database of all hospitalized patients in acute care and longer-term care units of a university hospital during a 21 -month period gave us the opportunity to reliability assess this impact. Follow-up was considered satisfactory, because $98 \%$ of the patients could traced at 60 days after the date of inclusion. We chose the 60-day period because the average length of stay in the hospital increased by 32 days in cases of severe NI (bloodstream infection or pneumonia). ${ }^{30}$ However, in-hospital mortality alone does not seem sufficient to study the real relationship between NI and mortality. ${ }^{31}$

Our study showed that NI remained significantly associated with death after adjustment for the McCabe score and the other confounding factors (OR, 1.7 [95\% CI, 1.4-2.2]). If we assume that the incidence of $\mathrm{NI}$ is approximately $3 \%-6 \%$ in the French hospitalized population, the PAR would reach $2.1 \%-4.0 \%$; in other words, of each 1,000 deaths in hospi- talized patients, $21-40$ would be attributable to NI. The risk factors with the strongest association seemed to be bloodstream infection (aOR, 2.9 [95\% CI, 1.5-5.7]), pneumonia (aOR, $2.495 \% \mathrm{CI}, 1.4-4.3 \mathrm{~J})$, and multiple sites of infection (aOR, 2.7 [95\% CI, 1.5-4.9]). Although the OR for death from UTI was low, these infections were common and therefore were involved in a significant number of deaths.

Several methodological points may have affected our results. First, it was impossible to strictly respect the pairing criteria with regard to time from admission to study inclusion and with regard to whether a patient stayed in an acute-care bed or a long-term care bed. It would have been even more difficult to pair subjects by the ward of hospitalization. In a hospital cohort of patients with pneumonia, ${ }^{14}$ the pairing of patients without NI based on 3 criteria was difficult: for 100 patients, only 74 matches could be found. We have therefore chosen not to skew our sample and to control for the confounding factors by adjustment.

Second, the clinical condition of the patient at admission to the hospital is the principal confounding factor. The condition of the patient is usually linked to the disease that led to hospitalization and to the comorbidities. We were unable to adjust for all these factors because of the diversity of the diseases in our study cohort. The McCabe score and the Charlson index, which are 2 predictive scores of short-term mortality (at 1 year), appeared to be the most promising methods to account for the severity of underlying disease.

We included these 2 severity scores in the various tested models to account for the redundancy of information. Thus, a model with the McCabe score and a model with the Charlson index were tested. These models showed slight differences in the estimation of the link between NI and death. Whereas the Charlson index is based on comorbidities, the McCabe score is more subjective, but it seems more robust. The model 
that adjusted for the McCabe score had the best goodness of fit. For this reason, we have chosen to base our analysis on the McCabe score.

Third, we estimated the relative risks as ORs, using the logistic models. ORs estimate relative risk best when the frequency of the outcome in the population is low (less than $10 \%) .^{32}$ In our study, the rate of death in the Nîmes University Hospital population is approximately $2 \%$, which is consistent with that described for all hospitals. The attributable fraction of risk depends on the frequency of exposure to the risk factor considered. In our study, the incidence of NI was approximately $2.8 \%$, corresponding to the lower limit of the interval usually considered.

Finally, it would be impossible to include every single NI that occurred in any hospital. But given the method we used, the number missed is unlikely to significantly change the results.

Our results are partially consistent with those of GarciaMartin et al., ${ }^{33}$ who studied mortality attributable to NI in a university hospital. The ranking of mortality risk they found in their study was similar to ours. After adjustment, the risk of death was highest for bloodstream infections (adjusted OR, 5.3 [95\% CI, 2.0-13.8]), followed by pneumonia (adjusted OR, 3.8 [95\% CI, 1.5-4.9]), and then infection at multiple sites (adjusted OR, 4.4 [95\% CI, 1.6-11.9]). These ORs were higher than ours; however, the case-control design may have overestimated the relative risks because of differential classification bias for the presence of an NI and other covariates. Garcia-Martin et al. ${ }^{33}$ estimated the risk attributable to NI using an adapted case-control study that measured the incidence of NI only in deceased patients. ${ }^{34}$ This approach leads to results that are generally less accurate because of the retrospective nature of the study. In their study, the adjusted PAR of death attributable to NI was $21.3 \%$ (95\% CI, 16.8 30.5 ), which is higher than that in our study. This finding may be the result of both a higher adjusted OR and a greater number of infections among patients who died at the hospital.

Most studies on the mortality attributable to NI have focused on bloodstream infections, ${ }^{7-10}$ pneumonia, ${ }^{11,12,14}$ and mostly in ICUs. ${ }^{5-12}$ A significant relative risk of death associated with bloodstream infection ${ }^{7,9}$ and pneumonia ${ }^{11,12}$ remained after adjustment for confounding factors in both studies, but the PAR was higher in the studies regarding bloodstream infections. Studies performed solely in ICUs, however, cannot be strictly compared with our study, because the PAR is linked to the chosen population. It would be expected, then, that the population of ICU-only patients would be more susceptible to infection than a hospital-wide population.

The only relevant French multicenter study ${ }^{4}$ was descriptive. This study analyzed, in 2001, 1945 deaths in 16 university or regional institutions. After excluding patients with a short life expectancy, the number with certain NIs, as evaluated by experts, was estimated to be $2.8 \%$. Extrapolation of these results to the population of hospitalized patients in France yields an percentage of deaths certainly attributable to NI of $2.4 \%$ for general hospitals and $3.4 \%$ for university hospitals. This last estimate falls between our limits of $2.1 \%$ and $4.0 \%$.

In our study, we found a significant risk of death linked to UTI. Although the relative risk of death from UTI is low, the extent of our study probably explains the statistical significance. The size effect is however low. Our ability to document a large number of UTIs likely led to a more accurate accounting of their contribution to mortality.

We cannot absolutely prove the link between NI and mortality. However, we have satisfied most of the criteria necessarily for establishing a causal link in observational studies: strength of association, temporal association, dose-response effect, lack of major bias, biological plausibility, and coherence with other studies.

In conclusion, it seems that the risk of death associated with NI remains significant despite adjustment for the principal confounding factors. Although the number of deaths attributable to NI appears less than previously thought, the high incidence of NI still results in a sizeable number of deaths. Multicenter studies will be needed to confirm these results.

Address reprint requests to Pascale Fabbro-Peray, $\mathrm{MD}, \mathrm{PhD}$, Département de l'Information Médicale, CHU de Nîmes, Bâtiment polyvalent, Place du Pr Debré, 30029 NIMES Cedex 9, France (p.fabbro.peray@chu-nimes.fr).

\section{ACKNOWLEDGMENTS}

We thank Isabelle Blanc and Olivier Marès, for the data collection and the databases management; the expert committee who reviewed all the deaths of patients with nosocomial infection (Robert Cohendy, Jean Carlet, Joseph Hajjar, Olivier Jonquet, Jacques Jourdan, Vincent Le Moing, and Benoît de Wazières); Régis Lossouarn, for capturing the data; and all the medical and paramedical staff at Nîmes University Hospital, for their collaboration. We thank Claudia Kaye for her helpful assistance in preparing the English manuscript.

This study was supported by the Ministère de la Santé, Programme hospitalier de recherche Clinique, Agence Nationale d'Accréditation et d'Evaluation en Santé, and Fondation pour la Recherche Médicale.

\section{REFERENCES}

1. Glynn A, Ward V, Wilson J, et al. Hospital Acquired Infection: Surveillance Policies and Practice. London, England: Public Health Laboratory Service; 1997.

2. Galvez-Vargas R, Bueno-Cavanillas A, Garcia-Martin M. Epidemiology, therapy and costs of nosocomial infection. Pharmacoeconomics 1995; 7: 128-140.

3. Circulaire DGS/VS/VS2-DH/E01- $\mathrm{N}^{\circ} 17$ du 19 avril 1995 relative à la lutte contre les infections nosocomiales dans les établissements de santé publics ou privés participant à l' exécution du service public. 1995. Available at: http:/www.sante.gouv.fr/htm/pointsur/nosoco/nosoco3-2-1.html. Accessed May 5, 2006.

4. Kaoutar B, Joly C, L'Heriteau F, et al. Nosocomial infections and hospital mortality: a multicentre epidemiology study. J Hosp Infect 2004; 58:268-275.

5. Vincent JL, Bihari DJ, Suter PM, et al. The prevalence of nosocomial infection in intensive care units in Europe: results of the European Prev- 
alence of Infection in Intensive Care (EPIC) Study. EPIC International Advisory Committee. JAMA 1995; 274:639-644.

6. Fagon JY, Chastre J, Vuagnat A, Trouillet JL, Novara A, Gibert C. Nosocomial pneumonia and mortality among patients in intensive care units. JAMA 1996; 275:866-869.

7. Pittet D, Tarara D, Wenzel RP. Nosocomial bloodstream infection in critically ill patients: excess length of stay, extra costs, and attributable mortality. JAMA 1994; 271:1598-1601.

8. Soufir L, Timsit JF, Mahe C, Carlet J, Regnier B, Chevret S. Attributable morbidity and mortality of catheter-related septicemia in critically ill patients: a matched, risk-adjusted, cohort study. Infect Control Hosp Epidemiol 1999; 20:396-401.

9. Renaud B, Brun-Buisson C. Outcomes of primary and catheter-related bacteremia: a cohort and case-control study in critically ill patients. Am J Respir Crit Care Med 2001; 163:1584-1590.

10. Digiovine $B$, Chenoweth $C$, Watts $C$, Higgins $M$. The attributable mortality and costs of primary nosocomial bloodstream infections in the intensive care unit. Am J Respir Crit Care Med 1999; 160:976-81.

11. Bercault N, Boulain T. Mortality rate attributable to ventilator-associated nosocomial pneumonia in an adult intensive care unit: a prospective case-control study. Crit Care Med 2001; 29:2303-2309.

12. Kollef MH, Silver P, Murphy DM, Trovillion E. The effect of late-onset ventilator-associated pneumonia in determining patient mortality. Chest $1995 ; 108: 1655-1662$.

13. Fagon JY, Chastre J, Domart Y, Trouillet JL, Gibert C. Mortality due to ventilator-associated pneumonia or colonization with Pseudomonas or Acinetobacter species: assessment by quantitative culture of samples obtained by a protected specimen brush. Clin Infect Dis 1996; 23:538-542.

14. Leu HS, Kaiser DL, Mori M, Woolson RF, Wenzel RP. Hospital-acquired pneumonia: attributable mortality and morbidity. Am J Epidemiol 1989; 129:1258-1267.

15. White MC. Mortality associated with nosocomial infections: analysis of multiple cause-of-death data. J Clin Epidemiol 1993; 46:95-100.

16. Comité Technique National des Infections Nosocomiales. 100 recommandations pour la surveillance et la prévention des infections nosocomiales. Paris, France: Secrétariat d'Etat à la santé et à l'action sociale; 1999. Available at: http://www.sante.gouv.fr/htm/pointsur/nosoco/nosoco3-1-2 .html. Accessed May 22, 2006.

17. Garner JS, Jarvis WR, Emori TG, Horan TC, Hughes JM. CDC definitions for nosocomial infections, 1988. Am J Infect Control 1988; 16:128-140.

18. McCabe WR, Jackson GG. Gram-negative bacteremia. Arch Intern Med $1962 ; 110: 847-864$.

19. Charlson ME, Pompei P, Ales KL, MacKenzie CR. A new method of classifying prognostic comorbidity in longitudinal studies: development and validation. J Chronic Dis 1987; 40:373-383.

20. Charlson M, Szatrowski TP, Peterson J, Gold J. Validation of a combined comorbidity index. J Clin Epidemiol 1994; 47:1245-1251.

21. Centre interregional de coordination pour la lutte contre les infections nosocomiales Sud Est. Available at: http://cclin-sudest.chu-lyon.fr. Accessed February 8, 2007.

22. Dinkel RH, Lebok U. A survey of nosocomial infections and their influence on hospital mortality rates. J Hosp Infect 1994; 28:297-304.

23. Legras B, Doveze P, Weber M. Evaluation of the mortality related to nosocomial infections: an approach by a homogeneous group of patients, from bacteriology and data of hospitalization (1989-1993) [in French]. Pathol Biol (Paris) 1996; 44:269-274.

24. Salemi C, Morgan J, Padilla S, Morrissey R. Association between severity of illness and mortality from nosocomial infection. Am J Infect Control 1995; 23:188-193.

25. Breslow NE, Day NE. The Design and Analysis of Cohort Studies: Statistical Methods in Cancer Research. Vol II. Lyon, France: IARC; 1987. Publication 2.

26. Hosmer WH, Lemeshow S. Applied Logistic Regression. New York, NY: John Wiley \& Sons; 1989.

27. Belsley DA, Kuh E, Welsch RE. Regression Diagnostics. New York, NY: John Wiley \& Sons; 1980.

28. Benichou J. Methods of adjustment for estimating the attributable risk in case-control studies: a review. Stat Med 1991; 10:1753-1773.

29. Abraham C, Daures JP, Momas I. Utilisation de la proportion de cas attribuable: intérêts, limites, et applications à une étude sur le cancer de la vessie dans l'Hérault. 1997. Available at: http://www.sfds.asso.fr/ publicat/somm97.htm. Accessed May 5, 2006.

30. Avril JL, Carlet J. Les infections nosocomiales et leur prévention. Paris, France: SA EM, 1998:687.

31. Poulsen KB, Wachmann CH, Bremmelgaard A, Sorensen AI, Raahave $D$, Petersen JV. Survival of patients with surgical wound infection: a casecontrol study of common surgical interventions. Br J Surg 1995; 82: 208-209.

32. Kleinbaum D, Kupper LL, Morgenstern H. Epidemiologic Research: Principles and Quantitative Methods. New York, NY: Van Nostrand Reinhold; 1982.

33. Garcia-Martin M, Lardelli-Claret P, Jimenez-Moleon JJ, Bueno-Cavanillas A, Luna-del-Castillo JD, Galvez-Vargas R. Proportion of hospital deaths potentially attributable to nosocomial infection. Infect Control Hosp Epidemiol 2001; 22:708-714.

34. Kuritz SJ, Landis JR. Attributable risk ratio estimation from matchedpairs case-control data. Am J Epidemiol 1987; 125:324-328. 